\title{
Neuropsychological and Behavioral Profiles in Attention-Deficit Hyperactivity Disorder Children of Parents with a History of Mood Disorders: A Pilot Study
}

\author{
Subin Park ${ }^{1}$, Kang-E M Hong ${ }^{2}$, Young Hui Yang ${ }^{3}$, Jewook Kang ${ }^{4}$, \\ Eun Jin Park ${ }^{5}$, Kyooseob Ha ${ }^{2}$, Mira Park ${ }^{6}$, and Hee Jeong Yoo ${ }^{2}$ \\ ${ }^{1}$ Division of Child and Adolescent Psychiatry, Department of Psychiatry, Seoul National University College of Medicine, Seoul, Republic of Korea \\ 2Department of Neuropsychiatry, Seoul National University Bundang Hospital, Seongnam, Republic of Korea \\ ${ }^{3}$ Department of Psychiatry, Pusan National University YangSan Children's Hospital, Yangsan, Republic of Korea \\ ${ }^{4}$ Department of Psychiatry, Inje University Busan Paik Hospital, Busan, Republic of Korea \\ ${ }^{5}$ Department of Psychiatry, Inje University Ilsan Paik Hospital, Goyang, Republic of Korea \\ ${ }^{6}$ Department of Preventive Medicine, Eulji University, Daejeon, Republic of Korea
}

Objective We aimed to investigate the neurocognitive and behavioral endophenotypes of premorbid mood disorder. We compared intelligence, neuropsychological functioning, and behavioral problems among three groups: 1) a high-risk group [attention-deficit hyperactivity disorder (ADHD) children of parents with a history of a mood disorder], 2) a low-risk group (ADHD children of parents without a history of a mood disorder), and 3) normal comparison subjects.

Methods We used the Korean Educational Development Institute Wechsler Intelligence Scale for Children-Revised (KEDI-WISC-R), the Stroop Color Word Interference Test (Stroop), the Wisconsin Card Sorting Test (WCST), and the Rey-Osterrieth Complex Figure Test (RCFT) as neurocognitive measures, and we used the Child Behavior Checklist (CBCL) as a behavioral measure. Performance on these neuropsychological tests and score on the CBCL of 18 high-risk children were compared to those of 20 low-risk children and 24 healthy children. We also assessed the children's current mood state and familial functioning to control for the confounding effects of these variables.

Results Compared to low-risk and healthy children, high-risk children were impaired on the Picture Completion and Stroop Word subtest and showed higher scores on the CBCL subscales representing internalizing symptoms. These significant group differences persisted even after adjustment for the children's current mood state and familial functioning.

Conclusion Neuropsychological deficits in the offspring of parents with a mood disorder may be associated with the current mood state rather than with innate characteristics, while their internalizing symptoms may partially stem from innate characteristics that are endophenotypes of a premorbid mood disorder.

Psychiatry Investig 2014;11:65-75

Key Words Mood disorder, Attention deficit hyperactivity disorder, Neuropsychology, Endophenotype, High-risk, Offspring.

\section{INTRODUCTION}

The children of parents with unipolar and bipolar affective disorders have notably high rates not only of mood disorders but also of other behavioral problems compared to the children of parents without mood disorders. ${ }^{1-8}$ The at-risk off-

Received: December 6, 2012 Revised: February 20, 2013

Accepted: February 21, 2013 Available online: January 21, 2014

$\triangle$ Correspondence: Hee Jeong Yoo, MD, PhD

Department of Neuropsychiatry, Seoul National University Bundang Hospital, 82 Gumi-ro 173beon-gil, Bundang-gu, Seongnam 436-707, Republic of Korea

Tel: +82-31-787-7436, Fax: +82-31-787-4058, E-mail: hjyoo@snu.ac.kr

(a) This is an Open Access article distributed under the terms of the Creative Commons Attribution Non-Commercial License (http://creativecommons.org/licenses/bync/3.0) which permits unrestricted non-commercial use, distribution, and reproduction in any medium, provided the original work is properly cited. spring of parents with a mood disorder - particularly bipolar disorder - also show neurocognitive deficits such as deficits in executive functioning, ${ }^{9-11}$ selective deficits in spatial memory and attention, ${ }^{9}$ and deficits in academic achievement. ${ }^{12}$ Possible causal relationships between parental mood problems and children's cognitive, emotional, and behavioral problems include genetic transmission, observational learning resulting from exposure to parental symptoms, and impaired parenting. ${ }^{1,13,14}$ Children's behavior problems could contribute to the development of parental depression. ${ }^{15}$

Attention-deficit hyperactivity disorder (ADHD) is a highly prevalent disorder in childhood with a significantly greater prevalence in the children of affectively ill parents. ${ }^{16-18}$ Family 
studies of ADHD and family studies of unipolar or bipolar affective disorders strongly support the assertion of a familial link between ADHD and unipolar or bipolar affective disorder. ${ }^{19-21}$ The high rates of ADHD in the offspring of parents with a mood disorder may have complicated the results of previous high-risk studies, ${ }^{1,2}$ which compared the children of parents with unipolar and/or bipolar affective disorder with the children of parents without these disorders. Thus, it is difficult to determine whether the specific neuropsychological and behavioral profiles observed in these children are characteristics of ADHD or are endophenotypes of a premorbid mood disorder. The possible effects of current mood state and familial functioning on the neuropsychological and behavioral characteristics of at-risk offspring could make it more difficult to determine whether the characteristics are innate or state-dependent.

Considering the limitations of these earlier high-risk studies, we compared the neuropsychological and behavioral profiles among the ADHD children of parents with a history of a mood disorder (high-risk group), those of parents without a history of a mood disorder (low-risk group), and healthy controls. We also examined the effects of possible mediating factors including the current mood state of the children and their parents as well as the familial relationship on the neuropsychological and behavioral problems of children with ADHD. We hypothesized that the high-risk groups would have specific neurocognitive deficits and behavioral profiles atypical for ADHD and independent of current mood state or familial functioning.

\section{METHODS}

\section{Subjects and procedures}

Psychiatric outpatients aged 6-15 years with a primary diagnosis of ADHD based on the Diagnostic and Statistical Manual of Mental Disorders, 4th Edition, Text Revision (DSMIV-TR ${ }^{22}$ were enrolled by a child psychiatrist in a general hospital located in Bundang, Seongnam City. A history of a mood disorder including major depressive disorder or bipolar disorder in their parents was obtained from a clinical interview of the parent by two board certified psychiatrists who have substantial clinical experience on a mood disorder for more than ten years, based on the DSM-IV-TR. ${ }^{22}$ Children with ADHD were classified into high- and low-risk groups according to the history of a mood disorder in their parents. Eighteen subjects (ages 7-15, mean \pm SD: 9.78+2.56; 15 males) were the offspring of parents with a history of a mood disorder (the high-risk group), and 20 subjects (age 6-15, mean \pm SD: 9.40+2.30; 17 males) had parents without a history of a mood disorder (the low-risk group).
Patients were excluded if they had any of the following: bipolar disorder or major depressive disorder; any other clinically significant Axis I disorders except for ADHD, tic disorder, oppositional defiant disorder, and mild depressive or anxiety disorders; mental retardation [Intelligence quotient $(\mathrm{IQ}) \leq 70$ on the Korean Educational Development Institute Wechsler Intelligence Scale for Children-Revised (KEDIWISC-R)]; language difficulties or developmental disorders including autism; a past or present history of brain damage, convulsive disorder or any neurological conditions affecting the results of the study.

$\mathrm{ADHD}$ and comorbid disorders were diagnosed using the Korean version of the Kiddle Schedule for Affective Disorders and Schizophrenia for School-Age Children-Present and Lifetime Version (K-SADS-PL). ${ }^{23}$ The Korean version of the K-SADS-PL was translated, and its validity and reliability for ADHD, tic disorders, and oppositional defiant disorder have been previously established. ${ }^{24}$ The severity of ADHD was assessed using the parent version of the Korean version of the ADHD Rating Scale (ADHD-RS). ${ }^{25}$ The ADHD-RS is an ADHD symptom severity scale composed of 18 items and designed by DuPaul ${ }^{26}$ according to the Diagnostic and Statistical Manual of Mental Disorders, 4th edition (DSM-IV) criteria. The ADHD-RS is composed of 9 items reflecting symptoms related to inattention and 9 items reflecting symptoms related to hyperactivity and impulsivity. Each item has a 4-point scale (0 to 3 ).

Twenty-four healthy children (20 boys, 4 girls; mean age, $9.37 \pm 1.50$ years) were recruited at an elementary school in the vicinity of our research center and were evaluated by a child psychiatrist. Control children were also screened for $\mathrm{ADHD}$ and other psychiatric disorders using the Korean version of the K-SADS-PL ${ }^{23}$ and the ADHD-RS. Exclusion criteria in the healthy controls were the same as those for the highand low-risk groups except that they were also excluded if they had ADHD. The age and gender distribution of the groups were not significantly different.

The study was approved by the institutional review board (IRB) for human subjects at the Seoul National University Bundang Hospital. Written informed consent was obtained from each child and the parent of each child.

\section{Measures}

\section{Neurocognitive measurements}

Subjects' cognitive functioning was assessed with the same battery of neuropsychological tests summarized in Table 1 . Detailed information about each neuropsychological test is as follows: 
Table 1. Tests and instruments in the neuropsychological battery

\begin{tabular}{ll}
\hline \multicolumn{1}{c}{ Neurocognitive function } & \multicolumn{1}{c}{ Test and instrument } \\
\hline General intelligence & KEDI-WISC-R verbal, performance, and full-scale IQ \\
Working memory & KEDI-WISC-R arithmetic and digit span \\
Processing speed & Stroop Word and color subtests \\
& KEDI-WISC-R digit symbol/coding \\
Interference control & Stoop color-word and interference \\
& WCST non-perseverative errors \\
Abstract thinking/set-shifting & KEDI-WISC-R similarity \\
& WCST perseverative errors and total errors \\
Visuo-spatial organization & RCFT copy organization and accuracy \\
& KEDI-WISC-R block design and object assembly \\
Visuo-spatial memory & RCFT immediate recall accuracy and delayed recall accuracy \\
Visual attention to fine detail & KEDI-WISC-R picture completion \\
Knowledge and verbal competence & KEDI-WISC-R information and vocabulary \\
Social awareness and judgment & KEDI-WISC-R comprehension and picture arrangement \\
\hline
\end{tabular}

KEDI-WISC-R: Korean Educational Development Institute Wechsler Intelligence Scale for Children-Revised, IQ: intellectual quotient, Stroop: Stroop Color Word Interference Test, WCST: Wisconsin Card Sorting Test, RCFT: Rey-Osterrieth Complex Figure Test

\section{The Korean Educational Development Institute Wechsler Intelligence Scale for Children-Revised}

The Korean Educational Development Institute Wechsler Intelligence Scale for Children-Revised (KEDI-WISC-R) ${ }^{27}$ consists of 5 verbal subtests, including Information, Similarities, Arithmetic, Vocabulary, and Comprehension, and 6 performance subtests, including Digit Span, Picture Completion, Picture Arrangement, Block Design, Object Assembly, and Digit Symbol/Coding. The Verbal Intelligence Quotient (IQ), Performance IQ, Full-Scale IQ (FSIQ), and 11 scaled scores of the subtests were calculated based on Korean age norms.

\section{Stroop Color Word Interference Test}

The Stroop Color Word Interference Test (Stroop) was developed by Charles Gordon for children ages 5 through $14 .^{28}$ The Korean version was standardized by Shin and Park. ${ }^{29}$ The test requires that children first read the words "red, green, blue" (Word subtest). Subsequently, they must state the colors of the letters making up the words "red, green, blue", which are written in concordant (Color subtest) or discordant colors (Color-Word subtest). The interference score is calculated from the correct number of concordant-colored letters (Color score) minus the correct number of discordant-colored letters (ColorWord score). All data are presented as T-scores adjusted for age and sex. Higher T-scores indicate better test performance.

\section{Wisconsin Card Sorting Test}

The Wisconsin Card Sorting Test (WCST) ${ }^{30}$ is a neuropsychological test used to measure executive function. The WCST requires the development and maintenance of precise prob- lem-solving strategies under various test conditions. In summary, subjects are given four stimulus cards with symbols differing in color, form, and number and are instructed to match 128 response cards with different colors, shapes, and number combinations to one of the stimulus cards according to a specific criterion (color, form, or number). Subjects are not informed of the criterion but are told after each trial whether the match is correct. The criteria are shifted in order of color, form, and number after 10 consecutive correct selections. This procedure is repeated until six criteria are passed. We used the total, perseverative, and non-perseverative errors. Perseveration involves the subject sorting the cards consecutively in the same way or repeating the previous principle.

\section{Rey-Osterrieth Complex Figure Test}

The Rey-Osterrieth Complex Figure Test (RCFT) ${ }^{31,32}$ was used to assess visuo-spatial constructional ability, visual memory, and executive function, particularly focusing on visual organizational strategies. The testing procedure was as follows. In the first stage, the participants saw a figure and copied it without knowing that they would be asked to remember the stimuli. After $3 \mathrm{~min}$ (immediate condition) and $30 \mathrm{~min}$ (delayed condition), a free recall test was given. Scoring was based on the standard system, in which the figure is partitioned into 18 structural units and on a global system of overall organization (five levels);. ${ }^{33}$ We used the copy organization score (higher scores indicate worse organization) and the immediate and delayed recall accuracy scores (higher scores indicate better recall). 


\section{Behavioral measurements}

\section{Child Behavior Checklist}

The Child Behavior Checklist (CBCL) developed by Achenbach and Edlebrock, ${ }^{34}$ which has been translated into Korean, was used to investigate several domains of psychopathology in the subjects. The CBCL is a parent-report questionnaire in which the child is rated on various behavioral and emotional problems. The reliability and validity of the Korean version of the CBCL (K-CBCL) are well-established in the Korean child and adolescent literature. ${ }^{35}$ It assesses internalizing (i.e., anxious, depressive, and overcontrolled) and externalizing (i.e., aggressive, hyperactive, noncompliant, and undercontrolled) behaviors. Several subareas are measured, including social withdrawal, somatic complaints, anxiety and depression, social problems, thought problems, attention problems, delinquent behavior, and aggressive behavior. The K-CBCL score was computed based on Korean normative samples, with the total problem behavior score computed by summing the scores obtained for each item. ${ }^{35}$

\section{Possible mediating factors}

\section{Children's mood state}

Neuropsychological functioning and behavioral problems in subjects may be affected by mood state. Levels of depression, mania, and anxiety could be different across the groups even though none of them meet the full criteria for major depressive disorder, bipolar disorder or anxiety disorders. Therefore, we assessed current mood state using the Children's Depression Inventory (CDI), ${ }^{36}$ the Child Bipolar Questionnaire (CBQ), ${ }^{37}$ and the State Anxiety Scale of the State-Trait Anxiety Inventory for Children (STAIC-S) ${ }^{38}$ and investigated the effects of moods and anxiety on the neuropsychological functioning and behavioral problems of the subjects.

\section{Children's Depression Inventory}

The CDI consists of 27 self-rated questions with a Likert scale from 0 (not present) to 2 (present and marked); total scores can range from 0 to $54 .{ }^{39}$ The item domains include negative mood, interpersonal problems, negative self-esteem, ineffectiveness, and anhedonia. The Korean version of the CDI was standardized by Cho and Lee, ${ }^{36}$ and its validity and reliability in Korean have been well established. A total score of 29 is considered the cutoff point for severe depressive symptoms in the Korean version.

\section{Child Bipolar Questionnaire}

The CBQ is a parent report form that consists of 65 items with a Likert scale from 1 (never) to 4 (nearly always). ${ }^{40}$ The majority of the CBQ's items are drawn from the DSM-IV criteria for mania and major depression, but symptoms of common comorbid conditions, such as anxiety and behavior disorders, are also represented. The CBQ total score is the total number of CBQ items rated 3 (often) or 4 (nearly always). A total score of 32 is considered the cutoff point for probable pediatric bipolar disorder, and a higher total score indicates a more severe mood disturbance. The Korean version of the CBQ was standardized by Cheon et al., ${ }^{37}$ and its validity and reliability in Korean have been well established.

\section{State Anxiety Scale of the State-Trait Anxiety Inventory for Children}

The STAIC-S consists of 20 self-rated questions that measure the level of anxiety. ${ }^{41}$ The STAIC-S asks subjects to describe how they feel at the present time and how their anxiety increases in response to situational stress and declines under relaxed conditions. The Korean version of the STAIC-S was standardized by Cho and Choi, ${ }^{38}$ who established a total score of 49 as the cutoff value for severe anxiety symptoms.

\section{Family and parental factors}

If parents with a history of mood disorders provide poor rearing and a dysfunctional relationship with their child, it is unclear whether their child's impairment is due to generic and biological factors or parental and environmental factors. Therefore, we assessed familial functioning using the Family Relationship Scale (FRS) ${ }^{42}$ and investigated its effect on the neuropsychological and behavioral functioning of subjects. Furthermore, the current mood state of parents with a history of a mood disorder may also affect the psychopathology of children. Therefore, we also assessed the parents' current mood state using the Beck Depression Inventory (BDI), the Mania scale of the Minnesota Multiphasic Personality Inventory-2 (MMPI-2), and State-Trait Anxiety Inventory (STAI). These data were only obtained from the low- and high-risk groups.

\section{Family Relationship Scale}

The FRS was developed by Yang (2001) to measure the familial relationship and consists of 24 self-rated questions with a Likert scale from 1 (never) to 5 (nearly always). ${ }^{42}$ It was constructed with three dimensions of 'love and care, 'recognition and responsibility', and 'acceptance and respect.' Higher total scores indicate a healthy and functioning family relationship. Its validity and reliability in Korean has been well established and previously reported. ${ }^{42,43}$ The FRS was rated by a child in all three groups. 
Beck Depression Inventory

The BDI consists of 21 items and measures the subjective severity of depression and the emotional, cognitive, motivational, and physiological symptoms of depression. ${ }^{44}$ Each question has a set of 4 possible answer choices, ranging in intensity, with each answer being scored on a scale value of 0 (no symptom) to 3 (the most severe symptom). Accordingly, the total score ranges from 0 to 63 for the 21 questions. In Korea, Han et $a{ }^{45}$ conducted a standardization study. The BDI was completed by parents of low- and high-risk children.

\section{Hypomania scale of the MMPI-2 (Ma)}

The MMPI- $2^{46}$ is a psychopathology assessment device consisting of 567 true/false items designed to assess a number of psychological, behavioral, and social constructs as well as testtaking attitudes and response style. In Korea, Han et al. ${ }^{47}$ conducted a standardization study. In this study, we used only Ma, a dimension that measures the level of excitability. The MMPI2 was measured by parents of low- and high-risk children.

State Anxiety Scale of the State-Trait Anxiety Inventory

The STAI-S is a 20 -item self-report scale used to measure the temporary condition of state-anxiety. ${ }^{48}$ The Korean version of the STAI-S was standardized by Han et al. ${ }^{49}$ The STAI-S was completed by parents of low- and high-risk children.

\section{Statistical analysis}

Group differences were computed using an independent ttest or a one-way analysis of variance (ANOVA) for continuous variables and a Chi-square or Fisher's exact test for categorical variables. Despite the small sample size, most measures were distributed normally according to the KolmogorovSmirnov test ( $\mathrm{p}$ values ranged from 0.108 to 0.962 ), except for the total score on the CBQ $(\mathrm{z}=1.57, \mathrm{p}=0.014)$ and scores on thought problems of the CBCL $(\mathrm{z}=1.74, \mathrm{p}=0.005)$. Taking these results into account, the nonparametric Kruskal-Wallis $\mathrm{H}$ test for the CBQ and the thought problems of the CBCL and a parametric one-way ANOVA for the rest of the measures initially performed to compare the three groups.

In the second stage, we used analyses of covariance (ANCOVA) to determine whether scores on the neuropsychological or behavioral measures were significantly different among the three groups when adjusted for possible confounders. Two models were used to explore the group effects on the neuropsychological measures: Model 1 included age and gender as covariates; Model 2 included CDI, CBQ, and STAIC-S scores (mood ratings) as well as age and gender as covariates. Previous work has demonstrated associations between childhood behavioral problems and lower cognitive ability ${ }^{50-52}$ as well as current mood state and familial functioning. There- fore, we included the FSIQ as a covariate in the analyses to explore the group effects on the behavioral measure as follows: Model 1' included age, gender, and FSIQ as covariates; Model 2' included mood ratings as well as age, gender, and FSIQ as covariates; Model 3' included familial functioning ratings as well as age, gender, and mood ratings as covariates.

In the third stage, we compared mood ratings (BDI, Ma, and STAI-S) of parents of the low- and high-risk groups using an independent T-test. Despite the small sample size, all measures were distributed normally according to the KolmogorovSmirnov test ( $\mathrm{p}$ values ranged from 0.306 to 0.952 ). An independent t-test revealed that only the maternal BDI score was significantly different between groups (mean \pm SD: $9.85 \pm 4.41$, in the low-risk group and $18.38 \pm 10.36$ in the high-risk group, $\mathrm{t}=2.74, \mathrm{p}=0.015$ ). Therefore, we conducted ANCOVA using the maternal BDI as a covariate to determine whether the scores on the behavioral measures were significantly different between the low- and high-risk groups, regardless of the level of maternal current depression.

All statistical analyses were performed using SPSS (version 12.0; SPSS Inc., Chicago, IL, USA), with statistical significance defined as an alpha level $=0.01$, to provide some control for type I error.

\section{RESULTS}

\section{Characteristics of the study participants}

In the high-risk group, twelve $(66.7 \%)$ children had a mother with a history of MDD, three (16.7\%) had a father with a history of MDD, two (11.1\%) had a mother with a history of bipolar I disorder, and one (5.6\%) child had both a mother and father with histories of MDD. Table 2 shows group-specific demographic and clinical characteristics. The age and gender distribution of the groups were not significantly different. Psychiatric comorbidity was highest in the high-risk group. As expected, scores on the ADHD-RS and the CBQ were significantly higher in both the high- and lowrisk group compared to the control group, but they did not significantly differ between the high- and low-risk groups. Scores on the STAIC-S did not differ among the three groups. Scores on the CDI and the FRS were significantly higher in the high-risk group compared to the control group, but they did not significantly differ between the high and low-risk groups.

\section{Neuropsychological test findings}

Means and standard deviations of all neuropsychological test scores appear in Table 3 for each group. The three groups were significantly different on the KEDI-WISC-R Picture Completion $(\mathrm{F}=7.18, \mathrm{df}=2.59, \mathrm{p}=0.002)$, Block Design 
$(\mathrm{F}=5.55, \mathrm{df}=2.59, \mathrm{p}=0.006), \mathrm{FSIQ}(\mathrm{F}=5.06, \mathrm{df}=2.59, \mathrm{p}=0.009)$ and Stoop Word subtest scores $(\mathrm{F}=6.85, \mathrm{df}=2.59, \mathrm{p}=0.002)$. Post hoc Tukey HSD revealed that the high-risk group had lower KEDI-WISC-R Picture Completion, Block Design, and Stroop Word subtest scores than both the control and lowrisk groups.

Table 2. Demographic and clinical characteristics among control and ADHD children of parents with and without a history of a mood disorder

\begin{tabular}{|c|c|c|c|c|c|c|}
\hline & $\begin{array}{l}\text { Normal Control } \\
\qquad(\mathrm{N}=24)\end{array}$ & $\begin{array}{l}\text { Low-risk group } \\
\qquad(\mathrm{N}=20)\end{array}$ & $\begin{array}{l}\text { High-risk group } \\
\quad(\mathrm{N}=18)\end{array}$ & \multirow[t]{2}{*}{$\chi^{2}$} & \multirow[t]{2}{*}{$\mathrm{p}$} & \\
\hline & \multicolumn{3}{|c|}{$\mathrm{N}(\%)$} & & & \\
\hline Gender, male & $20(88.3)$ & $17(88.2)$ & $15(88.3)$ & 0.03 & 0.986 & \\
\hline ADHD, type & & & & 2.72 & 0.256 & \\
\hline Combined & - & $17(85.0)$ & $13(72.2)$ & & & \\
\hline Inattentive & - & $2(10.0)$ & $5(27.8)$ & & & \\
\hline Hyperactive-impulsive & - & $1(5.0)$ & - & & & \\
\hline Comorbid disorder & & & & 0.23 & 0.894 & \\
\hline Tic disorder & - & $2(10.0)$ & $3(16.7)$ & & & \\
\hline Depressive disorder, NOS & - & $1(5.0)$ & $2(11.1)$ & & & \\
\hline ODD & - & $1(5.0)$ & $3(16.7)$ & & & \\
\hline ADHD medication & & & & 3.94 & 0.140 & \\
\hline No use & - & $1(5.0)$ & $3(16.7)$ & & & \\
\hline Methylphenidate & - & $16(80.0)$ & $15(83.3)$ & & & \\
\hline Atomoxetine & - & $3(15.0)$ & $0(0)$ & & & \\
\hline \multicolumn{7}{|l|}{ Other medication } \\
\hline No use & - & $16(80.0)$ & $9(50.0)$ & 3.79 & 0.087 & \\
\hline Atypical antipsychotic & - & $3(15.0)$ & $8(44.4)$ & 3.99 & 0.074 & \\
\hline Antidepressant & - & $2(10.0)$ & $1(5.6)$ & 0.26 & $>0.99$ & \\
\hline \multirow[t]{2}{*}{ Mood stabilizer } & - & $1(5.0)$ & $1(5.6)$ & 0.07 & $>0.99$ & \\
\hline & & Mean (SD) & & $\mathrm{F}(2,59)$ or $\mathrm{t}$ & $\mathrm{p}$ & Contrasts \\
\hline Age, years & $9.37(1.50)$ & $9.40(2.30)$ & $9.78(2.56)$ & 0.22 & 0.803 & \\
\hline Dose of ADHD medication (mg) & - & $35.37(17.67)$ & $35.40(15.96)$ & -0.01 & 0.996 & \\
\hline \multicolumn{7}{|l|}{ ADHD Rating Scale } \\
\hline Inattentive & $3.00(2.73)$ & $9.72(5.90)$ & $11.72(5.55)$ & 19.11 & $<0.001$ & $\mathrm{NC}<\mathrm{LR}, \mathrm{HR}$ \\
\hline Hyperactive-impulsive & $3.48(3.38)$ & $9.94(4.80)$ & $11.94(6.19)$ & 17.71 & $<0.001$ & $\mathrm{NC}<\mathrm{LR}, \mathrm{HR}$ \\
\hline Total & $6.48(5.91)$ & $19.67(10.40)$ & $23.67(10.98)$ & 20.34 & $<0.001$ & $\mathrm{NC}<\mathrm{LR}, \mathrm{HR}$ \\
\hline CDI & $8.65(4.85)$ & $13.22(7.68)$ & $16.78(7.74)$ & 7.49 & 0.001 & $\mathrm{NC}<\mathrm{HR}$ \\
\hline CBQ & $3.79(5.79)$ & $14.25(13.63)$ & $18.94(11.56)$ & $20.44^{*}$ & $<0.001$ & $\mathrm{NC}<\mathrm{LR}, \mathrm{HR}$ \\
\hline STAIC-S & $30.70(4.53)$ & $31.22(7.02)$ & $33.39(10.09)$ & 0.73 & 0.487 & \\
\hline FRS & $101.57(14.66)$ & $92.94(14.66)$ & $83.24(16.04)$ & 7.24 & 0.002 & $\mathrm{NC}<\mathrm{HR}$ \\
\hline Maternal BDI & & $9.85(4.41)$ & $18.38(10.36)$ & 2.74 & 0.015 & \\
\hline Maternal Ma & & $46.93(7.76)$ & $46.57(8.11)$ & 0.12 & 0.903 & \\
\hline Maternal STAI-S & & $44.31(7.93)$ & $50.33(11.55)$ & 1.53 & 0.139 & \\
\hline Paternal BDI & & $5.17(4.76)$ & $9.90(9.10)$ & 1.59 & 0.128 & \\
\hline Paternal Ma & & $48.79(10.79)$ & $47.50(12.20)$ & 0.29 & 0.778 & \\
\hline Paternal STAI-S & & $37.50(9.79)$ & $40.18(10.30)$ & 0.64 & 0.529 & \\
\hline
\end{tabular}

${ }^{*} \chi^{2}$ (Kruskal-Wallis H test). ADHD: attention-deficit hyperactivity disorder, ODD: oppositional defiant disorder, NOS: not otherwise specified, CDI: Children's Depression Inventory, CBQ: child bipolar questionnaire, STAIC-S: State Anxiety Scale of the State-Trait Anxiety Inventory for Children, FRS: family relationship scale, BDI: Beck Depression Inventory, Ma: hypomania scale of the Minnesota Multiphasic Personality Inventory-2, STAI-S: State-Anxiety Inventory, NC: normal control, LR: low-risk group, HR: high-risk group 
S Park et al.

Table 3. Intelligence and neuropsychological tests among control and ADHD children of parents with and without a history of a mood disorder

\begin{tabular}{|c|c|c|c|c|c|c|}
\hline & \multirow{2}{*}{$\begin{array}{c}\text { Normal Control } \\
(\mathrm{N}=24)\end{array}$} & \multirow{2}{*}{$\begin{array}{l}\text { Low risk group } \\
\qquad \begin{array}{c}(\mathrm{N}=20) \\
\text { Mean }(\mathrm{SD})\end{array}\end{array}$} & \multirow{2}{*}{$\begin{array}{l}\text { High risk group } \\
(\mathrm{N}=18) \\
\text { Mean }(\mathrm{SD})\end{array}$} & \multicolumn{2}{|c|}{ ANOVA } & \multirow{2}{*}{ Contrasts } \\
\hline & & & & $\mathrm{F}(2,59)$ & $\mathrm{p}$ & \\
\hline \multicolumn{7}{|l|}{ KEDI-WISC-R } \\
\hline Information & $13.04(2.68)$ & $13.35(4.23)$ & $10.28(3.46)$ & 4.53 & 0.015 & \\
\hline Similarities & $13.11(3.21)$ & $13.35(3.15)$ & $12.39(4.16)$ & 0.64 & 0.530 & \\
\hline Arithmetic & $11.75(2.07)$ & $11.70(2.66)$ & $9.67(3.41)$ & 3.72 & 0.030 & \\
\hline Vocabulary & $12.96(2.80)$ & $13.00(3.76)$ & $11.35(4.11)$ & 1.31 & 0.279 & \\
\hline Comprehension & $11.58(2.38)$ & $10.90(3.19)$ & $11.11(3.79)$ & 0.28 & 0.755 & \\
\hline Digit span & $10.29(3.28)$ & $10.25(2.40)$ & $10.61(3.84)$ & 0.07 & 0.931 & \\
\hline Picture completion & $10.96(2.66)$ & $10.79(2.49)$ & $8.06(2.84)$ & 7.18 & 0.002 & $\mathrm{NC}, \mathrm{LR}>\mathrm{HR}$ \\
\hline Picture arrangement & $12.04(2.77)$ & $10.85(2.81)$ & $10.33(3.25)$ & 1.91 & 0.157 & \\
\hline Block design & $14.54(2.41)$ & $14.10(2.57)$ & $11.56(4.05)$ & 5.55 & 0.006 & $\mathrm{NC}, \mathrm{LR}>\mathrm{HR}$ \\
\hline Object assembly & $12.63(2.26)$ & $11.90(3.23)$ & $11.22(3.14)$ & 1.25 & 0.294 & \\
\hline Digit symbol/coding & $12.75(2.67)$ & $11.40(2.58)$ & $10.72(3.32)$ & 2.8 & 0.069 & \\
\hline Verbal IQ & $116.17(10.60)$ & $115.70(17.17)$ & $105.39(20.23)$ & 2.78 & 0.07 & \\
\hline Performance IQ & $114.58(24.00)$ & $113.45(13.89)$ & $102.78(19.58)$ & 2.07 & 0.136 & \\
\hline Full scale IQ & $119.58(10.00)$ & $116.25(16.27)$ & $104.50(20.41)$ & 5.06 & 0.009 & $\mathrm{NC}>\mathrm{HR}$ \\
\hline \multicolumn{7}{|l|}{ Stroop (t-scores) } \\
\hline Word & $47.17(7.00)$ & 47.95 (10.95) & $38.22(9.01)$ & 6.85 & 0.002 & $\mathrm{NC}, \mathrm{LR}>\mathrm{HR}$ \\
\hline Color & $48.50(8.21)$ & $47.95(10.06)$ & $41.61(14.23)$ & 2.42 & 0.098 & \\
\hline Color-word & $46.33(11.45)$ & $49.30(10.22)$ & $43.67(10.60)$ & 1.29 & 0.283 & \\
\hline Interference & $49.17(9.85)$ & $52.05(9.30)$ & $52.44(11.82)$ & 0.66 & 0.52 & \\
\hline \multicolumn{7}{|l|}{ WCST } \\
\hline Total errors & $53.96(9.97)$ & $50.00(10.10)$ & $50.06(9.96)$ & 1.14 & 0.328 & \\
\hline Perseverative errors & $54.79(10.11)$ & $51.90(10.67)$ & $51.78(8.54)$ & 0.66 & 0.522 & \\
\hline Non-perseverative errors & $51.58(9.61)$ & $47.80(9.64)$ & $47.72(9.71)$ & 1.15 & 0.323 & \\
\hline \multicolumn{7}{|l|}{ RCFT } \\
\hline Copy organization & $7.21(2.30)$ & $5.90(2.88)$ & $6.89(2.78)$ & 1.41 & 0.182 & \\
\hline Immediate recall accuracy & $20.17(9.66)$ & $21.50(8.43)$ & $17.56(10.34)$ & 0.84 & 0.436 & \\
\hline Delayed recall accuracy & $20.25(9.17)$ & $22.10(7.91)$ & $18.39(9.29)$ & 0.84 & 0.437 & \\
\hline
\end{tabular}

ADHD: attention-deficit hyperactivity disorder, KEDI-WISC-R: Korean Educational Development Institute Wechsler Intelligence Scale for Children-Revised, IQ: intellectual quotient, Stroop: Stroop Color Word Interference Test, WCST: Wisconsin Card Sorting Test, RCFT: ReyOsterrieth Complex Figure Test, NC: normal control, LR: low-risk group, HR: high-risk group, ANOVA: analysis of variance

The ANCOVA Model 1 revealed that significant group differences on KEDI-WISC-R Picture Completion ( $\mathrm{F}=5.83$, $\mathrm{df}=$ 2,59, $\mathrm{p}=0.005)$ and Block Design $(\mathrm{F}=5.68, \mathrm{df}=2,59, \mathrm{p}=0.006)$ subscales and Stoop Word subtest scores $(\mathrm{F}=6.96, \mathrm{df}=2,59$, $\mathrm{p}=0.002$ ) persisted even after adjustment for age and gender. After further adjustment for mood ratings (Model 2), the only Stroop Word subtest score differed significantly among the three groups $(\mathrm{F}=5.24, \mathrm{df}=2,59, \mathrm{p}=0.009)$.

We conducted additional analyses including the FSIQ as a covariate to evaluate whether the difference in the Stroop Word subtest could be explained by the difference in IQ among the three groups. After further adjustment for IQ, the
Stroop word subtest score was not different among the three groups $\left(\mathrm{F}=3.18, \mathrm{df}=2,59, \mathrm{p}=0.049\right.$ in Model $1^{\prime} ; \mathrm{F}=3.44, \mathrm{df}=$ 2,59, $\mathrm{p}=0.040$ in Model 2'; $\mathrm{F}=3.14, \mathrm{df}=2,59, \mathrm{p}=0.052$ ).

\section{Behavioral measurement findings}

The mean and standard deviation of each CBCL score appears in Table 4 for each group. The three groups were significantly different for all subscale scores of the CBCL ( $<<0.001)$. Post hoc Tukey HSD revealed that the high-risk group had higher somatization, anxiety/depression, internalizing problems, and total behavioral problems scores than the control and low-risk groups. 
Table 4. Child behavior checklist among control and ADHD children of parents with and without a history of a mood disorder

\begin{tabular}{|c|c|c|c|c|c|c|}
\hline & \multirow{2}{*}{$\begin{array}{l}\text { Normal Control } \\
\qquad(\mathrm{N}=24) \\
\text { Mean }(\mathrm{SD})\end{array}$} & \multirow{2}{*}{$\begin{array}{l}\text { Low risk group } \\
\qquad(\mathrm{N}=20) \\
\text { Mean }(\mathrm{SD})\end{array}$} & \multirow{2}{*}{$\begin{array}{l}\text { High risk group } \\
\qquad(\mathrm{N}=18) \\
\text { Mean }(\mathrm{SD})\end{array}$} & \multicolumn{2}{|c|}{ ANOVA } & \multirow{2}{*}{ Contrasts } \\
\hline & & & & $\mathrm{F}(2,52)$ & $\mathrm{p}$ & \\
\hline Withdrawal & $46.86(5.84)$ & $55.84(12.90)$ & $62.93(13.58)$ & 9.79 & $<0.001$ & $\mathrm{NC}, \mathrm{LR}<\mathrm{HR}$ \\
\hline Somatization & $45.64(6.32)$ & $50.63(7.60)$ & $57.07(7.07)$ & 11.66 & $<0.001$ & $\mathrm{NC}, \mathrm{LR}<\mathrm{HR}$ \\
\hline Anxiety/depression & $45.18(7.68)$ & $54.89(7.79)$ & $62.57(7.48)$ & 22.91 & $<0.001$ & $\mathrm{NC}<\mathrm{LR}<\mathrm{HR}$ \\
\hline Social problems & $43.05(5.75)$ & $58.53(8.95)$ & $61.86(9.57)$ & 30.14 & 0.001 & $\mathrm{NC}<\mathrm{LR}, \mathrm{HR}$ \\
\hline Thought problems & $48.18(5.89)$ & $52.89(7.49)$ & $58.29(8.34)$ & $15.73^{*}$ & $<0.001$ & $\mathrm{NC}<\mathrm{HR}$ \\
\hline Attention problems & $44.05(8.03)$ & $59.58(6.89)$ & $64.71(9.32)$ & 33.93 & $<0.001$ & $\mathrm{NC}<\mathrm{LR}, \mathrm{HR}$ \\
\hline Delinquent behavior & $44.36(7.09)$ & $55.68(10.03)$ & $60.71(12.53)$ & 13.74 & $<0.001$ & $\mathrm{NC}<\mathrm{HR}$ \\
\hline Aggressive behavior & $41.86(7.55)$ & $59.16(9.29)$ & $64.29(9.88)$ & 33.75 & $<0.001$ & $\mathrm{NC}<\mathrm{LR}, \mathrm{HR}$ \\
\hline Internalizing problems & $44.18(7.98)$ & $54.47(6.97)$ & $62.14(8.06)$ & 24.64 & $<0.001$ & $\mathrm{NC}<\mathrm{LR}<\mathrm{HR}$ \\
\hline Externalizing problems & $41.68(8.00)$ & $58.47(6.97)$ & $65.29(8.71)$ & 36.84 & $<0.001$ & $\mathrm{NC}<\mathrm{LR}, \mathrm{HR}$ \\
\hline Total behavior problem & $41.77(7.85)$ & $57.11(6.90)$ & $65.00(7.68)$ & 45.53 & $<0.001$ & $\mathrm{NC}<\mathrm{LR}<\mathrm{HR}$ \\
\hline
\end{tabular}

${ }^{*} \chi^{2}$ (Kruskal-Wallis H test). NC: normal control, LR: low-risk group, HR: high-risk group, ANOVA: analysis of variance

The ANCOVA (Model 1') revealed that all of these significant group differences persisted after adjustment for age, gender, and FSIQ [i.e., somatization ( $\mathrm{F}=11.02, \mathrm{df}=2,59, \mathrm{p}<0.001)$, anxiety/depression $(\mathrm{F}=22.13, \mathrm{df}=2,59, \mathrm{p}<0.001)$, internalizing problems $(\mathrm{F}=25.29, \mathrm{df}=2,59, \mathrm{p}<0.001)$, and total behavioral problems $(F=44.68, d f=2,59, p<0.001)]$. Even after further adjustment for mood (Model 2') and familial functioning ratings (Model 3'), comparisons of the three groups on the CBCL subscale scores mostly remained significantly below the 0.01 level [i.e., in Model 3': somatization $(\mathrm{F}=5.05, \mathrm{df}=2,59, \mathrm{p}=$ 0.011 ), anxiety/depression ( $\mathrm{F}=10.80, \mathrm{df}=2,59, \mathrm{p}<0.001)$, internalizing problems $(\mathrm{F}=10.94, \mathrm{df}=2,59, \mathrm{p}<0.001)$, and total behavioral problems $(\mathrm{F}=18.42, \mathrm{df}=2,59, \mathrm{p}<0.001)$; detailed data of Model 2' not shown, but available upon request].

In the sub-analyses of the low- and high-risk groups using ANCOVA, significant between-group differences were shown in the scores on depression/anxiety $(\mathrm{F}=13.01, \mathrm{df}=1,36, \mathrm{p}=$ $0.001)$, internalizing problems $(\mathrm{F}=8.37, \mathrm{df}=1,36, \mathrm{p}=0.008)$, and total behavioral problems $(\mathrm{F}=8.67, \mathrm{df}=1,36, \mathrm{p}=0.007)$, even after adjustment for maternal BDI.

\section{DISCUSSION}

The major finding of this study is that the ADHD children of parents with a history of mood disorders were more anxious/depressed and exhibited more internalizing problems compared to controls and ADHD children of parents without a history of a mood disorder. This pattern of behavioral problems was also noted even after adjustment for the child's FSIQ, mood symptoms, and familial functioning ratings. Another major finding is that the ADHD children of parents with a history of mood disorders exhibited deficits in the Picture
Completion and Block Design subtests of the KEDI-WISC and the Word subtest of the Stroop, although this pattern of deficits was not noted after adjustment for the child's mood symptoms or intelligence. The findings of this study provide an important first step in attempting to examine the neuropsychological and behavioral correlates associated with a group of high-risk children, in this case, the ADHD offspring of parents with a history of mood disorders.

Previous studies have indicated that individuals with a mood disorder had minimal to no impairment on standard measures of current or estimated premorbid intellectual functioning, suggesting that the cognitive deficit profile in a mood disorder does not involve gross intellectual decline..$^{53}$ There are a few studies that have examined intellectual functioning in the offspring of parents with unipolar or bipolar disorders. Kron et al..$^{54}$ and McDonough-Ryan et al..$^{12}$ reported no group difference in FSIQ between the offspring of parents with bipolar disorder and controls. In contrast, Klimes-Dougan et al. ${ }^{9}$ reported lower FSIQ scores in the offspring of parents with bipolar disorder compared to a control group, but not in the offspring of parents with unipolar disorder. Micco et al. ${ }^{55}$ also reported no group difference in FSIQ between the offspring of parents with major depression and controls. In this study, the high-risk group showed lower FSIQ scores than the control group, but there was no significant difference in FSIQ between the low- and high-risk groups. These findings suggest the combined effect of ADHD and a family history of a mood disorder on general intellectual functioning.

The results of cognitive studies in the offspring of parents with unipolar or bipolar disorders are inconsistent. KlimesDougan et al. ${ }^{9}$ found impairment on the WCST (categories, perseverative errors, total errors), the RCFT (only recall or- 
ganization), and the continuous performance test (only total errors) in the offspring of mothers with a history of a mood disorder, suggesting deficits in executive functioning and spatial memory and attention. MacQueen et al. ${ }^{10}$ found that affected offspring with a history of a mood disorder showed poorer performance in the visual backward masking task, but non-affected offspring performed the task at the levels of healthy controls. Micco et al. ${ }^{55}$ also found that parents' major depression was not associated with children's neuropsychological impairments, although affected offspring showed poor performance on several executive functioning and processing speed measures.

In this study, high-risk children were impaired on the Picture Completion, Block Design, and Stroop Word subtest in comparison to the low-risk group and control group. However, differences on the Stroop Word subtest could be explained by the difference in IQ among the three groups, and group differences on the Picture Completion and Block Design subscales disappeared after an adjustment for mood ratings. Picture Completion measures visual perception and the ability to determine whether the missing part is either essential or a function of the object, and Block Design measures visuo-spatial ability. ${ }^{56}$ Our findings suggest that impairments of visual attention to fine detail and visuo-spatial ability may be characteristic cognitive deficits present in the children of parents with a mood disorder, without regard to their ADHD status. However, those cognitive deficits may be affected by the current mood state rather than being innate. These results are consistent with the previous studies that reported cognitive deficits in affected offspring but not in unaffected offspring. ${ }^{10,55}$

Although all subscale scores of the CBCL were significantly higher in high-risk children than in healthy controls, the difference between the high- and low-risk groups was shown only in subscales representing internalizing symptoms such as somatization, anxiety/depression, and internalizing problems. In addition, these differences persisted even after adjustment for current familial functioning and maternal mood state as well as after adjustment for the child's IQ and mood state, suggesting that the offspring of affectively ill parents have an innate propensity for internalizing symptoms. These results favor the genetic transmission of a mood component in ADHD children who suffer from internalizing symptoms. This finding is in contrast with one prominent theory about the relationship between ADHD and depression, that the social/interpersonal difficulties experienced by many children with ADHD may predispose them to develop depressive symptoms. $^{57}$

Unexpectedly, there were no significant differences in neurocognitive profiles between healthy controls and ADHD children of parents without a history of a mood disorder, al- though between-group differences were significant in their behavioral profiles. Neurocognitive deficits including poor motor control, working memory problems, difficulties with inhibiting behavioral responses and processing speed deficits have been widely implicated and documented in ADHD populations. ${ }^{58-60}$ It is possible that a more commonly used test of attention not utilized in this study, such as the continuous performance test, might have revealed a difference between normal controls and the low-risk ADHD group. In addition, the fact that most ADHD subjects were medicated may have narrowed the cognitive discrepancies between normal controls and ADHD children. However, both the low- and high-risk groups were medicated and the dose of ADHD medication was not significantly different between two groups; therefore, medication effects may not have impacted the cognitive comparison between the low- and high-risk groups. Although the high-risk group showed a trend of more use of atypical antipsychotics compared to the low-risk group, atypical antipsychotic appears to have no detrimental effect on cognitive performance in children. ${ }^{61}$

We extended the findings of previously studied high-risk offspring using a more narrowly defined high-risk group characterized by ADHD and a family history of a mood disorder, using both healthy controls and ADHD children without a family history of a mood disorder as comparison groups, and by adjusting for the influence of mood ratings and familial functioning when assessing cognitive and behavioral group differences.

Several limitations may have influenced the findings in this study. First, as in most other studies addressing this topic, multiple comparisons were made. We presented the results with an alpha level of .01 because of the exploratory nature of this study and the need to balance the risk for type I and type II error. Second, we included the offspring of parents with both unipolar and bipolar disorders in the high-risk group. If we had included only the offspring of parents with a history of unipolar or of bipolar disorder, our high-risk group would have been more homogeneous. In addition, we did not have adequate statistical power to compare subjects with a depressed parent and a bipolar parent because we had too few subjects with bipolar parents. Third, we also did not control for comorbid disorders and type of ADHD in our analyses because our sample size did not afford sufficient power to include such covariates. Forth, our ADHD sample is drawn from a relatively affluent population of medicated children attending a psychiatric outpatient clinic of a general hospital. Group differences between healthy control and ADHD children might be even more pronounced in a more diverse sample. However, group differences between low- and high-risk groups may not be influenced by this range restriction, as 
suggested above. Finally, because only a subset of these cases of at-risk offspring, ranging from 5 to $67 \%$, developed a mood disorder, ${ }^{62}$ long-term studies are needed to confirm the premorbid endophenotypes of mood disorders.

Despite these considerations, this preliminary study adds to a growing body of work documenting the neurocognitive and behavioral characteristics of at-risk offspring who have parents with a mood disorder. Neuropsychological deficits in the offspring of parents with a mood disorder may be associated with the current mood state rather than with innate characteristics, while their internalizing symptoms may partially stem from innate characteristics that are endophenotypes of a premorbid mood disorder. In terms of clinical implications, ADHD children exhibiting internalizing symptoms need detailed assessments for mood disorder, and they are good candidates for receiving preventive interventions aimed at altering the prognosis of the illness.

\section{Acknowledgments}

This study was supported by grant No. 02-2008-011 from the Seoul National University Bundang Hospital Research Foundation.

\section{REFERENCES}

1. Chang KD, Steiner H, Ketter TA. Psychiatric phenomenology of child and adolescent bipolar offspring. J Am Acad Child Adolesc Psychiatry 2000;39:453-460.

2. Sachs GS, Baldassano CF, Truman CJ, Guille C. Comorbidity of attention deficit hyperactivity disorder with early- and late-onset bipolar disorder. Am J Psychiatry 2000;157:466-468.

3. Anderson CA, Hammen CL. Psychosocial outcomes of children of unipolar depressed, bipolar, medically ill, and normal women: a longitudinal study. J Consult Clin Psychol 1993;61:448-454.

4. Billings AG, Moos RH. Social-environmental factors among light and heavy cigarette smokers: a controlled comparison with nonsmokers. Addict Behav 1983;8:381-391.

5. Goodman SH. Depression in mothers. Annu Rev Clin Psychol 2007;3: 107-135.

6. Goodman SH, Brogan D, Lynch ME, Fielding B. Social and emotional competence in children of depressed mothers. Child Dev 1993;64:516531 .

7. Goodman SH, Rouse MH, Connell AM, Broth MR, Hall CM, Heyward D. Maternal depression and child psychopathology: a meta-analytic review. Clin Child Fam Psychol Rev 2011;14:1-27.

8. Hammen C, Gordon D, Burge D, Adrian C, Jaenicke C, Hiroto D. Maternal affective disorders, illness, and stress: risk for children's psychopathology. Am J Psychiatry 1987;144:736-741.

9. Klimes-Dougan B, Ronsaville D, Wiggs EA, Martinez PE. Neuropsychological functioning in adolescent children of mothers with a history of bipolar or major depressive disorders. Biol Psychiatry 2006;60:957965.

10. MacQueen GM, Grof P, Alda M, Marriott M, Young LT, Duffy A. A pilot study of visual backward masking performance among affected versus unaffected offspring of parents with bipolar disorder. Bipolar Disord 2004;6:374-378.

11. Meyer SE, Carlson GA, Wiggs EA, Ronsaville DS, Martinez PE, Klimes-Dougan B, et al. A prospective high-risk study of the association among maternal negativity, apparent frontal lobe dysfunction, and the development of bipolar disorder. Dev Psychopathol 2006;18:573589 .
12. McDonough-Ryan P, DelBello M, Shear PK, Ris DM, Soutullo C, Strakowski SM. Academic and cognitive abilities in children of parents with bipolar disorder: a test of the nonverbal learning disability model. J Clin Exp Neuropsychol 2002;24:280-285.

13. Downey G, Coyne JC. Children of depressed parents: an integrative review. Psychol Bull 1990;108:50-76.

14. Lovejoy MC, Graczyk PA, O’Hare E, Neuman G. Maternal depression and parenting behavior: a meta-analytic review. Clin Psychol Rev 2000; 20:561-592.

15. Lyons-Ruth K, Zoll D, Connell D, Grunebaum HU. The depressed mother and her one-year-old infant: environment, interaction, attachment, and infant development. New Dir Child Dev 1986:61-82.

16. Biederman J, Petty C, Hirshfeld-Becker DR, Henin A, Faraone SV, Dang D, et al. A controlled longitudinal 5-year follow-up study of children at high and low risk for panic disorder and major depression. Psychol Med 2006;36:1141-1152.

17. Radke-Yarrow M, Nottelmann E, Martinez P, Fox MB, Belmont B. Young children of affectively ill parents: a longitudinal study of psychosocial development. J Am Acad Child Adolesc Psychiatry 1992;31:6877.

18. Hammen C, Burge D, Burney E, Adrian C. Longitudinal study of diagnoses in children of women with unipolar and bipolar affective disorder. Arch Gen Psychiatry 1990;47:1112-1117.

19. Biederman J, Faraone S, Mick E, Wozniak J, Chen L, Ouellette C, et al. Attention-deficit hyperactivity disorder and juvenile mania: an overlooked comorbidity? J Am Acad Child Adolesc Psychiatry 1996;35:9971008 .

20. Faraone SV, Biederman J. Do attention deficit hyperactivity disorder and major depression share familial risk factors? J Nerv Ment Dis 1997; 185:533-541.

21. Faraone SV, Biederman J, Mennin D, Russell R. Bipolar and antisocial disorders among relatives of $\mathrm{ADHD}$ children: parsing familial subtypes of illness. Am J Med Genet 1998;81:108-116.

22. Amerian Psychiatric Association. Diagnostic and Statistical Mannual of Mental Disorders, fourth edition, text-revision. Washington, DC: Amerian Psychiatric Association; 2000.

23. Kaufman J, Birmaher B, Brent D, Rao U, Flynn C, Moreci P, et al. Schedule for Affective Disorders and Schizophrenia for School-Age Children-Present and Lifetime Version (K-SADS-PL): initial reliability and validity data. J Am Acad Child Adolesc Psychiatry 1997;36:980988.

24. Kim YS, Cheon KA, Kim BN, Chang SA, Yoo HJ, Kim JW, et al. The reliability and validity of Kiddie-Schedule for Affective Disorders and Schizophrenia-Present and Lifetime Version- Korean version (K-SADSPL-K). Yonsei Med J 2004;45:81-89.

25. So YK, Noh JS, Kim YS, Ko SG, Koh YJ. The reliability and validity of Korean Parent and Teacher ADHD Rating Scale. J Korean Neuropsychiatr Assoc 2002;41:283-289.

26. DuPaul GJ. Parent and teacher ratings of ADHD symptoms: psychometric properties in a community-based sample. J Clin Child Psychol 1991;20:245-253.

27. Park K, Yoon J, Park H. The Manual of Korean Educational Development Institute-Wechsler Intelligence Scale for Children-Revised. Seoul: Korean Educational Development Institute; 1991.

28. Golden CJ. A group version of the Stroop Color and Word Test. J Pers Assess 1975;39:386-388

29. Shin MS, Park MJ. Stroop Color and Word Test, a Manual for Clinical and Experimental Uses. Seoul: Hakjisa; 2007.

30. Heaton RK. Wisconsin Card Sorting Test Manual: Revised and Expanded. Odessa, FL: Psychological Assessment Resources; 1993.

31. Shin MS, Park SY, Park SR, Seol SH, Kwon JS. Clinical and empirical applications of the Rey-Osterrieth Complex Figure Test. Nat Protoc 2006;1:892-899.

32. Lezak MD. Neuropsychological assessement. New York, NY: Oxford University Press; 1995. 
33. Waber DP, Holmes JM. Assessing children's copy productions of the Rey-Osterrieth Complex Figure. J Clin Exp Neuropsychol 1985;7:264280.

34. Achenbach TM. Manual for the Child Behavior Checklist/4-18 and 1991 Profile. Burlington, Vermont: University of Vermont Department of Psychiatry; 1991.

35. Oh KJ, Lee H, Hong KE, Ha EH. K-CBCL. Seoul, Korea: Chung Ang Aptitude Publishing Co; 1997.

36. Cho SC, Lee YS. Development of the Korean version of Children's Depression Inventory. J Korean Neuropsychiatr Assoc 1990;29:943-956.

37. Cheon KA, Shin DW, Kim B, So YS, Jun JY, Song DH. The reliability and validity of the Child Bipolar Questionnaire 2.0 (CBQ 2.0)-Korean version. J Korean Neuropsychiatr Assoc 2008;47:269-278.

38. Cho SC, Choi JS. Development of the Korean version of State-Trait Anxiety Inventory for children. Seoul Rev Psychiatry 1989;14:150-157.

39. Kovacs M. The Children's Depression, Inventory (CDI). Psychopharmacol Bull 1985;21:995-998.

40. Papolos D, Hennen J, Cockerham MS, Thode HC Jr, Youngstrom EA. The child bipolar questionnaire: a dimensional approach to screening for pediatric bipolar disorder. J Affect Disord 2006;95:149-158.

41. Spielberger CD. Manual for the State-Trait Anxiety Inventory for Children. Palo Alto, CA: Consulting Psychological Press; 1972.

42. Yang OK. Study on development of the family relationship scale. J Korean Acad Fam Soc Work 2001;8:117-145.

43. Yang OK, Lee MY. The family relationship scale: re-validation. Korean J Soc Welfare 2003;54:5-33.

44. Beck AT, Ward CH, Mendelson M, Mock J, Erbaugh J. An inventory for measuring depression. Arch Gen Psychiatry 1961;4:561-571.

45. Han HM, Yom TH, Shin YW, Kim GH, Yoon DJ, Chung KJ. A standardization study of Beck Depression Inventory in Korea. J Korean Neuropsychiatr Assoc 1986;25:487-502.

46. Butcher NJ, Graham JR, Ben-Porath YS, Tellegen A, Dahlstrom WG, Kaemmer BK. MMPI-2 (Minnesota Multiphasic Personality Inventory 2): Manual for administration, scoring, and interpretation. Minneapolis: University of Minnesota Press; 2001.

47. Han KH, Lim JY, Min BB, Lee JH, Moon KJ, Kim ZS. Korean MMPI-2 standardization study. Korean J Clin Psychol 2006;25:533-564.

48. Spielberger CD. Manual for the State-Trait Anxiety Inventory (STAI). Palo Alto, CA: Consulting Psychologists Press; 1983.

49. Lee CH, Hahn DW, Chon KK. Korean Adaptation of Spielberger's STAI
(K-STAI). Korean J Health Psychol 1996;1:1-14.

50. Jacobs N, Rijsdijk F, Derom C, Danckaerts M, Thiery E, Derom R, et al. Child psychopathology and lower cognitive ability: a general population twin study of the causes of association. Mol Psychiatry 2002;7:368374.

51. Manikam R, Matson JL, Coe DA, Hillman N. Adolescent depression: relationships of self-report to intellectual and adaptive functioning. Res Dev Disabil 1995;16:349-364.

52. Leckliter IN, Matarazzo JD. The influence of age, education, IQ, gender, and alcohol abuse on Halstead-Reitan Neuropsychological Test Battery performance. J Clin Psychol 1989;45:484-512.

53. Bora E, Yucel M, Pantelis C. Cognitive endophenotypes of bipolar disorder: a meta-analysis of neuropsychological deficits in euthymic patients and their first-degree relatives. J Affect Disord 2009;113:1-20.

54. Kron L, Decina P, Kestenbaum CJ, Farber S, Gargan M, Fieve R. The offspring of bipolar manic-depressives: clinical features. Adolesc Psychiatry 1982;10:273-291.

55. Micco JA, Henin A, Biederman J, Rosenbaum JF, Petty C, Rindlaub LA, et al. Executive functioning in offspring at risk for depression and anxiety. Depress Anxiety 2009;26:780-790.

56. Wechsler D. The Measurement of Adult Intelligence. Baltimore, MD: Williams \& Witkins; 1939.

57. Ostrander R, Crystal DS, August G. Attention deficit-hyperactivity disorder, depression, and self- and other-assessments of social competence: a developmental study. J Abnorm Child Psychol 2006;34:773787.

58. Barkley RA. Behavioral inhibition, sustained attention, and executive functions: constructing a unifying theory of ADHD. Psychol Bull 1997; 121:65-94.

59. Semrud-Clikeman M, Guy K, Griffin JD, Hynd GW. Rapid naming deficits in children and adolescents with reading disabilities and attention deficit hyperactivity disorder. Brain Lang 2000;74:70-83.

60. Tannock R. Attention deficit hyperactivity disorder: advances in cognitive, neurobiological, and genetic research. J Child Psychol Psychiatry 1998;39:65-99.

61. Aman MG, Hollway JA, McDougle CJ, Scahill L, Tierney E, McCracken JT, et al. Cognitive effects of risperidone in children with autism and irritable behavior. J Child Adolesc Psychopharmacol 2008;18:227-236.

62. DelBello MP, Geller B. Review of studies of child and adolescent offspring of bipolar parents. Bipolar Disord 2001;3:325-334. 